\title{
Changes in Peripheral Refractive Profile after Orthokeratology for Different Degrees of Myopia
}

\author{
José Manuel González-Méijome ${ }^{1}$, Miguel A. Faria-Ribeiro ${ }^{1}$, Daniela P. Lopes-Ferreira ${ }^{1}$, \\ Paulo Fernandes ${ }^{1}$, Gonzalo Carracedo ${ }^{2}$ and Antonio Queiros ${ }^{1}$ \\ ${ }^{1}$ Clinical \& Experimental Optometry Research Lab, School of Sciences (Optometry), University of Minho, Braga, \\ Portugal and ${ }^{2}$ Department of Optics II (Optometry and Vision), School of Optics, Universidad Complutense de \\ Madrid, Madrid, Spain
}

\begin{abstract}
Purpose: The purpose of this study was to evaluate the effect of orthokeratology for different degrees of myopia correction in the relative location of tangential $\left(\mathrm{F}_{\mathrm{T}}\right)$ and sagittal $\left(\mathrm{F}_{\mathrm{S}}\right)$ power errors across the central $70^{\circ}$ of the visual field in the horizontal meridian.

Methods: Thirty-four right eyes of 34 patients with a mean age of $25.2 \pm 6.4$ years were fitted with Paragon CRT (Mesa, AZ) rigid gas permeable contact lenses to treat myopia $(-2.15 \pm 1.26 \mathrm{D}$, range: -0.88 to $-5.25 \mathrm{D})$. Axial and peripheral refraction were measured along the central $70^{\circ}$ of the horizontal visual field with the Grand Seiko WAM5500 open-field auto-refractor. Spherical equivalent $(M)$, as well as tangential $\left(\mathrm{F}_{\mathrm{T}}\right)$ and sagittal power errors $\left(\mathrm{F}_{\mathrm{S}}\right)$ were obtained. Analysis was stratified in three groups according to baseline spherical equivalent: Group $1\left[\mathrm{M}_{\text {Baseline }}=-0.88\right.$ to $\left.-1.50 \mathrm{D} ; n=11\right]$, Group $2\left[\mathrm{M}_{\text {Baseline }}=-1.51\right.$ to $\left.-2.49 \mathrm{D} ; n=11\right]$, and Group $3\left[\mathrm{M}_{\text {Baseline }}=-2.50\right.$ to $\left.-5.25 \mathrm{D} ; n=12\right]$.

Results: Spherical equivalent was significantly more myopic after treatment beyond the central $40^{\circ}$ of the visual field $(p<0.001) . \mathrm{F}_{\mathrm{T}}$ became significantly more myopic for all groups in the nasal and temporal retina with $25^{\circ}$ $(p \leq 0.017), 30^{\circ}(p \leq 0.007)$ and $35^{\circ}(p \leq 0.004)$ of eye rotation. Myopic change in $\mathrm{F}_{\mathrm{S}}$ was less consistent, achieving only statistical significance for all groups at $35^{\circ}$ in the nasal and temporal retina $(p \leq 0.045)$.

Conclusions: Orthokeratology changes significantly $\mathrm{F}_{\mathrm{T}}$ in the myopic direction beyond the central $40^{\circ}$ of the visual field for all degrees of myopia. Changes induced by orthokeratology in relative peripheral $M, \mathrm{~F}_{\mathrm{T}}$ and $\mathrm{F}_{\mathrm{S}}$ with $35^{\circ}$ of eye rotation were significantly correlated with axial myopia at baseline.
\end{abstract}

Keywords: Field curvature, myopia, orthokeratology, peripheral astigmatism

\section{INTRODUCTION}

Myopia affects approximately 25\% of the World population being a public health concern due to the socioeconomic impact and to the risk of vision loss related to other co-morbidities. ${ }^{1}$ For these reasons there is great interest in solutions to prevent myopia onset and progression. However, such approaches require knowledge of the mechanisms involved in order to optimize their success.
Presently, the most commonly accepted optical approach to interfere with myopia progression consists on myopia correction with reverse geometry contact lenses for corneal reshaping. ${ }^{2,3}$ Orthokeratology presents low rate of adverse events and is well accepted by parents and children. ${ }^{4,5}$ Several studies have shown lower annual increase of axial elongation of the eye in children wearing these lenses when compared with groups wearing spectacle lenses $^{6-8}$ or soft contact lenses. ${ }^{9}$

Received 31 October 2013; revised 16 December 2014; accepted 13 January 2015; published online 17 March 2015

Correspondence: José Manuel González-Méijome, Clinical \& Experimental Optometry Research Lab, School of Sciences (Optometry), Center of Physics (Optometry), University of Minho, 4710-057 Braga, Portugal. Tel: +351 2536040 72. Fax: +351 253604061 . E-mail:

jgmeijome@fisica.uminho.pt 
The hypothesized working mechanism that supports these results seems to be related to the myopic shift in the pattern of peripheral refraction, while maintaining a fully compensated central vision. ${ }^{10,11}$ This change will avoid the stimuli for ocular growth that allegedly is induced by a relative hyperopic error in the periphery as it has been proved in animal models. ${ }^{12-14}$ Bakaraju et al. have suggested that the risk for myopia progression could be higher in axial myopias compared to refractive ones according to their peripheral refractive pattern. ${ }^{15}$

Interestingly, pioneer work from Cho and coauthors found a positive and statistically significant correlation between baseline spherical equivalent refraction and vitreous chamber depth elongation in the orthokeratology group such that the higher the baseline myopia the lower the myopic progression. Conversely, the opposite was found in the control group of spectacle wearers. ${ }^{7}$ Similar results were found by Kakita et al. in their study conducted in Japan. They reported a statistically significant trend for higher myopes to present a smaller axial elongation over a period of 2 years, while no correlation between baseline myopia and axial length growth was found in the control spectacle wearing group over the same period of time. ${ }^{6}$ While this finding would reinforce the role of peripheral myopization in the myopic retention effect, potentially establishing a dose-response relationship, other studies with similar results in terms of retention of axial elongation failed to find such an effect. ${ }^{8}$ Results from Chen et al. found a relationship between scotopic pupil area and axial length growth, in a 2-year study comparing orthokeratology against single vision spectacle lenses; similar correlation was not found for the spectacle wearers in the same study. While other factors as increased effect of aberrations might be involved, the authors justified their findings with the fact that larger pupil size will enhance the effect caused by the peripheral corneal steepening on the myopization of the peripheral retina. $^{16}$

To this date, all the previous literature has analyzed the refractive outcomes of orthokeratology in terms of vectorial decomposition of refraction, while no study has paid attention to the relative field curvature of both extremes of the interval of Sturm represented by the tangential $\left(\mathrm{F}_{\mathrm{T}}\right)$ and sagittal $\left(\mathrm{F}_{\mathrm{S}}\right)$ focal lengths. The relative positions of the sagittal and tangential foci might be crucial to understand the mechanisms that guide the elongation of the eye. ${ }^{17-19}$ Indeed, a study conducted in rhesus monkeys suggested that the emmetropization mechanism might by guided by the astigmatic defocus instead of the spherical equivalent defocus. The results suggested that the growth mechanism might be guided by the image plane that contains the maximum effective contrast and stimulus orientation. ${ }^{20}$ In humans, the relative position of each focal lengths with respect to the retinal plane might provide a new insight in the understanding of the efficacy of myopia regulation with optical treatments. In this domain, tangential and sagittal focal lengths are more easily interpreted from the optical point of view than their vectorial counterparts in the form of horizontal (J0) and oblique (J45) components of the astigmatism. ${ }^{21}$

The present study aimed to evaluate the refractive changes in orthokeratology patients with different degrees of baseline myopia and correlate changes in sagittal and tangential power errors with baseline refraction.

\section{MATERIAL AND METHODS}

\section{Subjects and Inclusion Criteria}

Thirty-four right eyes of 34 university students (21 males and 13 females) mean age of $25.2 \pm 6.4$ years (ranging from 19 to 41), were evaluated. Pre-treatment spherical equivalent obtained with subjective refraction was $-2.15 \pm 1.26 \mathrm{D}$ (from $-5.25 \mathrm{D}$ to -0.88 ).

After explaining the nature of the study, each patient signed a consent form before being enrolled. The research followed the Declaration of Helsinki rules and was reviewed and approved by the Scientific Committee of the School of Sciences of Minho University (Portugal). The inclusion criteria required that the subjects did not suffer from any current eye disease or injury and were not taking any ocular or systemic medication. Monocular subjective refraction was performed. The criterion of maximum plus for best visual acuity was used to arrive to the end point of refraction.

\section{Peripheral Refraction}

The measurement of central and peripheral refraction was obtained with an open-field Grand Seiko AutoRefractometer/Keratometer WAM-5500 (Grand Seiko Co., Ltd., Hiroshima, Japan). This instrument was been previously used and validated to measure refraction in the central ${ }^{22,23}$ and peripheral retina. ${ }^{24}$ A software was created to automatically record data from the auto-refractometer, thus avoiding errors in data collection and allowing data to be automatically processed in Excel spreadsheet for later statistical process using appropriate software.

The illumination of the room was adjusted to obtain a pupil size greater than $4 \mathrm{~mm}$ required to allow the more peripheral measurements, which was achieved in all cases without pharmacological dilation. The fixation target was placed at a distance of $2.5 \mathrm{~m}$ from the patient's corneal vertex and consisted of 15 LEDs in the horizontal direction: one central, seven to the right and seven to the left side. The LEDs 
were separated from each other by an angular distance of $5^{\circ}$ at the patient's position. The subject was seated with the head stabilized in a chin-rest so that the eye was aligned with the central LED. For the right eye, the fixation of an object positioned on the right side of the central point matches the temporal retina measures and vice-versa. Along the paper, nasal and temporal refer to nasal and temporal retina locations for each degree of eye rotation. The left eye was occluded while patients kept their head stationary and rotated their right eyes to view the fixation targets. Five readings were taken from each eye and averaged considering the center of the pupil as the reference point of measurement. A minimum treatment period of 1 month was required to guarantee that the treatment was stable. $^{25}$ The time between pre- and post-treatment measures was $37.0 \pm 3.0 \mathrm{~d}$. Lenses were removed approximately $2 \mathrm{~h}$ before the measurements.

Descriptive statistics (mean $\pm S D$ ) were obtained for the refraction vector components according to Fourier analysis, as recommended by Thibos. ${ }^{21}$ Tangential and sagittal power errors were also calculated and correlated with changes in baseline refraction.

$$
\begin{aligned}
& \mathrm{F}_{\mathrm{T}}=\mathrm{M}+\mathrm{J}_{0} \\
& \mathrm{~F}_{\mathrm{S}}=\mathrm{M}-\mathrm{J}_{0}
\end{aligned}
$$

For the purpose of statistical analysis and data presentation, patients were stratified in three different groups according to their spherical equivalent refraction into Group 1 [SE $=-1.50$ to $-0.88 \mathrm{D} ; n=11$, Group 2 [SE $=-2.49 \mathrm{D}$ to $-1.51 ; n=11$ ], and Group 3 [SE $=-5.25 \mathrm{D}$ to $-2.50 ; n=12]$. Table 1 shows the demographic characteristics of each refractive group.

\section{Corneal Refractive Therapy Lens Characteristics}

Paragon $\mathrm{CRT}^{\mathrm{TM}}$ (paflufocon $\mathrm{D}, \mathrm{Dk}=100$ barrer) sigmoid reverse geometry rigid gas permeable lenses were used (Paragon Vision Sciences, Mesa, AZ).
Trial lenses were derived from sliding table monograms provided by the manufacturer and which have shown high levels of predictability in terms of first trial success. ${ }^{2}$ Fitting was evaluated according to the recommendations of the manufacturer regarding fluorescein pattern, topographical evaluation, refractive and visual outcomes.

\section{Statistical Analysis}

The SPSS software package v.17 (SPSS Inc., Chicago, IL) was used for statistical analysis. KolmogorovSmirnov Test was applied in order to evaluate the normality of data distribution. Due to the limited sample size in each sub-group, comparisons within each group were done using non-parametric statistical analysis. Correlation analysis was conducted between changes in the peripheral refraction (average between $35^{\circ}$ nasal and $35^{\circ}$ temporal retina) and axial spherical equivalent refraction (M) at baseline. Symmetry between refraction in the nasal and temporal retina were conducted using paired sample comparisons between values of the refractive components at the same eccentricity in both sides of the retina. For statistical purposes, a $p$ value lower than 0.05 was considered statistically significant.

\section{RESULTS}

All patients achieved successful correction (post-treatment $\mathrm{M}=-0.14 \pm 0.61 \mathrm{D}$ ) showing unaided visual acuity equal or better than $0.00 \mathrm{log}$-MAR.

Figure 1 shows the individual patterns of axial and relative peripheral refraction (RPRE) for $\mathrm{M}, \mathrm{F}_{\mathrm{T}}$ and $\mathrm{F}_{\mathrm{S}}$. Qualitative evaluation of the baseline RPRE reveals some degree of inter-subject variability (hyperopic and myopic profiles), across the central $70^{\circ}$ of the horizontal visual field. After treatment, field curvature increases for most of the eyes, shifting the RPRE in the myopic direction. Even so, $\mathrm{F}_{\mathrm{S}}$ remains either myopic or hyperopic at 30 and $35^{\circ}$ while $\mathrm{F}_{\mathrm{T}}$ becomes myopic for all eyes.

\begin{tabular}{|c|c|c|c|c|}
\hline Parameter & $\begin{array}{l}\text { Low myopes } \\
\text { (Group 1) }\end{array}$ & $\begin{array}{l}\text { Mild myopes } \\
\text { (Group 2) }\end{array}$ & $\begin{array}{l}\text { Moderate-high myopes } \\
\text { (Group 3) }\end{array}$ & $\begin{array}{c}p \\
\text { (significance) }\end{array}$ \\
\hline Number of subjects/eyes & 11 & 11 & 12 & \\
\hline Female; Male & $3 ; 8$ & $4 ; 7$ & $6 ; 6$ & 0.290 \\
\hline Age & $26.36 \pm 5.70[20 ; 36]$ & $26.00 \pm 8.93[19 ; 37]$ & $21.83 \pm 1.53[19 ; 25]$ & $0.335+$ \\
\hline$M$ & $-1.05 \pm 0.12[-0.88 ;-1.50]$ & $-1.74 \pm 0.31[-1.51 ;-2.49]$ & $-3.54 \pm 1.06[-2.50 ;-5.25]$ & $<0.001+$ \\
\hline J0 & $0.03 \pm 0.18[0.25 ;-0.23]$ & $0.08 \pm 0.11[0.32 ; 0.00]$ & $0.08 \pm 0.22[0.63 ;-0.31]$ & $0.783+$ \\
\hline $\mathrm{J} 45$ & $0.02 \pm 0.09[0.13 ;-0.25]$ & $0.00 \pm 0.10[0.22 ;-0.19]$ & $0.00 \pm 0.26[0.54 ;-0.43]$ & $0.732+$ \\
\hline $\mathrm{F}_{\mathrm{T}}$ & $-0.68 \pm 0.41[-0.14 ;-1.39]$ & $-1.41 \pm 0.31[-1.01 ;-2.01]$ & $-3.03 \pm 1.08[-2.26 ;-5.72]$ & $<0.001+$ \\
\hline $\mathrm{F}_{\mathrm{S}}$ & $-0.83 \pm 0.35[-0.24 ;-1.32]$ & $-1.69 \pm 0.60[-0.94 ;-2.71]$ & $-3.21 \pm 1.08[-2.09 ;-5.31]$ & $<0.001+$ \\
\hline
\end{tabular}

TABLE 1 Demographic data of subjects in each refractive group of low, moderate and high myopes.

Refractive error (M, J0 and J45) report data measured in primary gaze. Boldface: $p<0.05$. 

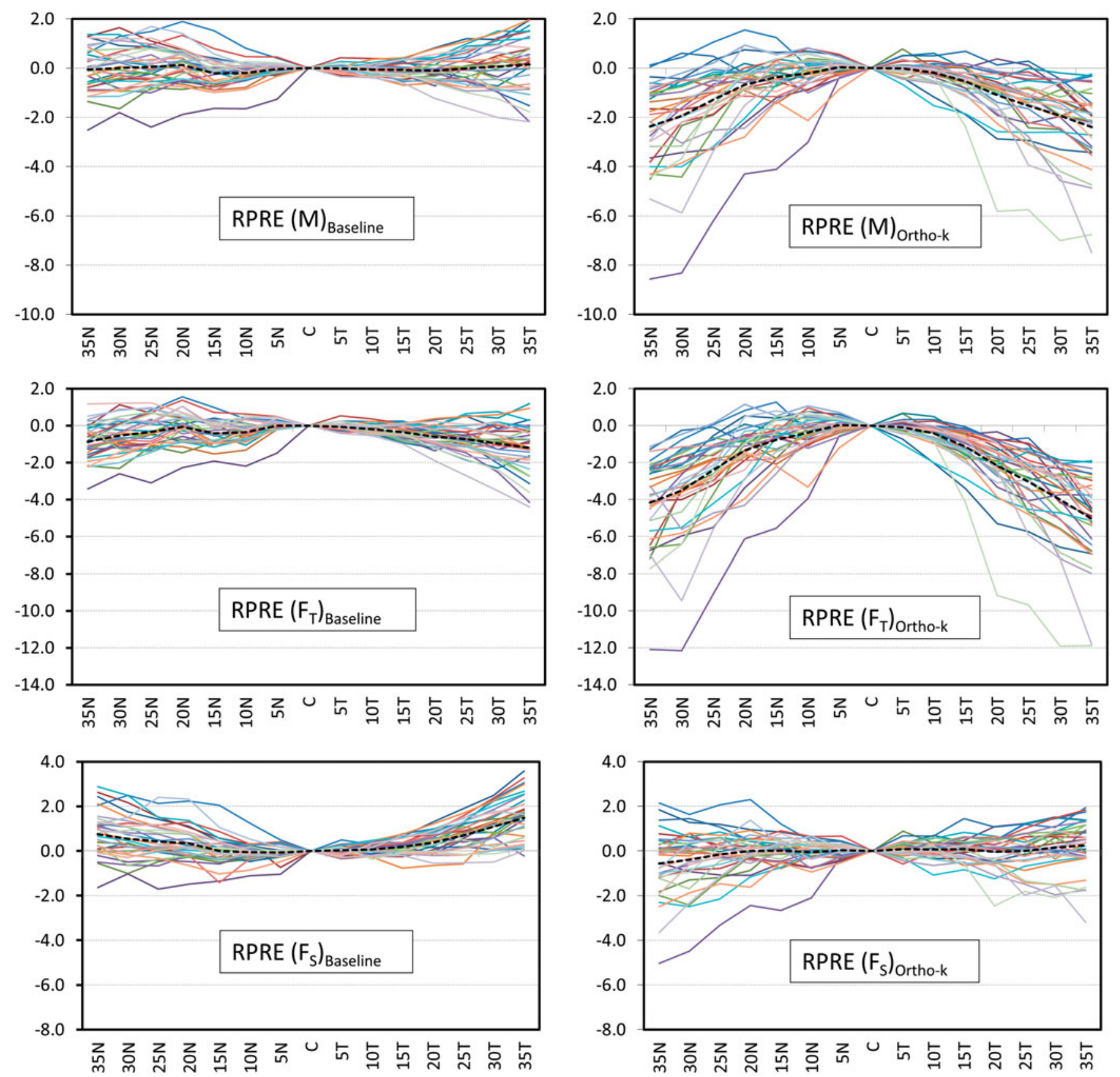

FIGURE 1 Individual relative peripheral refractive error before $\left(R P R E_{\text {Baseline }}\right)$ and after orthokeratology treatment (RPRE $\left.E_{\text {Ortho-k }}\right)$ for spherical equivalent $(\mathrm{M})$, tangential $\left(\mathrm{F}_{\mathrm{T}}\right)$ and sagittal $\left(\mathrm{F}_{\mathrm{S}}\right)$ power errors with different degrees of eye rotation $\left(35^{\circ}\right.$ temporal to $35^{\circ}$ nasal across the retina). Dashed lines (-) represent the average value for the whole sample. The plots represent the relative (not absolute) peripheral relative defocus (normalized to the central value) in order to make all graphs directly comparable.

Figure 2 shows the average RPRE for each one of the three refractive groups for $\mathrm{M}, \mathrm{F}_{\mathrm{S}}$ and $\mathrm{F}_{\mathrm{T}}$ components of refraction. Significance values for changes in RPRE from baseline to after treatment are shown in Table 2. $\mathrm{M}$ component was significantly more myopic after treatment beyond the central $40^{\circ}$ of the visual field $(p<0.001)$ for all groups. $\mathrm{F}_{\mathrm{T}}$ became significantly more myopic for all groups in the nasal and temporal retina with $25^{\circ}(p \leq 0.017), 30^{\circ}(p \leq 0.007)$ and $35^{\circ}(p \leq 0.004)$ of eye rotation. Groups 2 and 3 showed a significant myopic increase in $\mathrm{F}_{\mathrm{T}}$ in the nasal retina at $20^{\circ}$ of eye rotation $(p \leq 0.008)$ and with $10^{\circ}(p \leq 0.034)$, $15^{\circ}$ $(p \leq 0.007)$ and $20^{\circ}(p \leq 0.003)$ in the temporal retina. Myopic changes in $\mathrm{F}_{\mathrm{S}}$ component were less consistent, achieving only statistical significance for all groups at $35^{\circ}$ to both sides of the visual field $(p \leq 0.045)$.

The highly myopic group 3 achieved also significant myopization of $\mathrm{F}_{\mathrm{S}}$ at $20^{\circ}, 25^{\circ}$ and $30^{\circ}$ nasal and temporal retina $(p \leq 0.017)$. Values found are much lower than those reported for $\mathrm{F}_{\mathrm{T}}$ following a hyperopic trend for the central eccentricities of the visual field in some groups. 

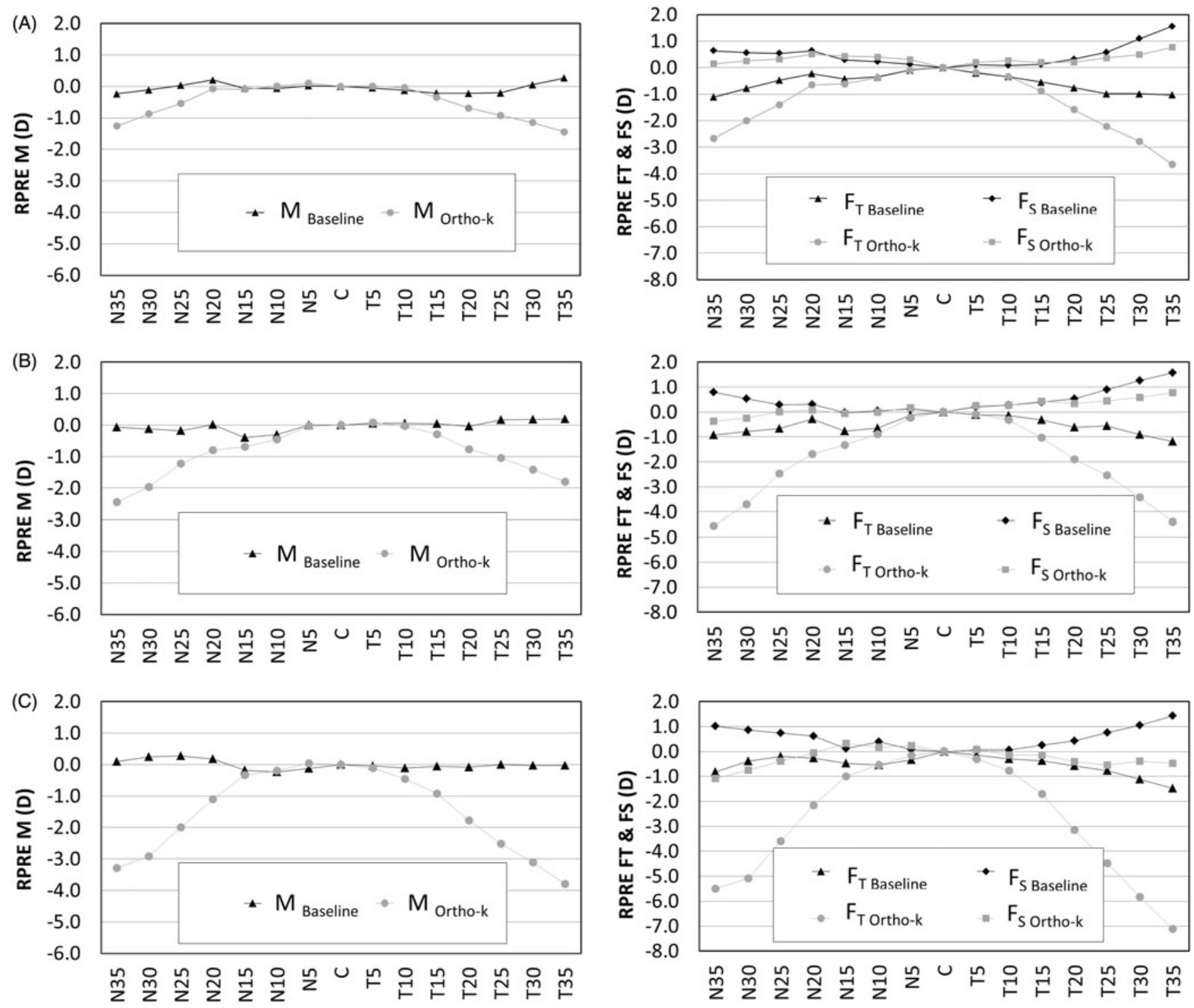

FIGURE 2 Average relative peripheral refractive error before ( $R P R E_{\text {Baseline; }}$ triangles/diamonds) and after orthokeratology treatment $\left(\mathrm{RPRE}_{\text {Ortho-k}}\right.$; squares/circles) for spherical equivalent $(\mathrm{M})$, tangential $\left(\mathrm{F}_{\mathrm{T}}\right)$ and sagittal $\left(\mathrm{F}_{\mathrm{S}}\right)$ power errors, with different degrees of eye rotation ( $35^{\circ}$ temporal to $35^{\circ}$ nasal across the retina). (A): low myopes; (B): moderate myopes; (C): high myopes. The plots represent the relative (not absolute) peripheral relative defocus (normalized to the central value) in order to make all graphs directly comparable.

It was observed a strong and statistically significant correlation between baseline central spherical equivalent $(\mathrm{M})$ and the change in the relative peripheral sagittal and tangential focal lengths at $30^{\circ}$ and $35^{\circ}$ of eccentricity. In the nasal visual field, the correlations between baseline central spherical equivalent and changes in relative peripheral $\mathrm{F}_{\mathrm{T}}$ and $\mathrm{F}_{\mathrm{S}}$ at $35^{\circ}$ and $30^{\circ}$ of eccentricity were $(r=0.470 ; p<0.001 ; r=0.567$; $p<0.001 ; r=0.518 ; p<0.001$ and $r=0.506 ; p<0.001$, respectively). In the temporal retina, the correlations between baseline central spherical equivalent and changes in relative peripheral $\mathrm{F}_{\mathrm{T}}$ and $\mathrm{F}_{\mathrm{S}}$ at $35^{\circ}$ and $30^{\circ}$ of eccentricity were $(r=0.837 ; p<0.001 ; r=0.777$; $p<0.001 ; r=0.558 ; p<0.001$ and $r=0.472 ; p<0.001$, respectively).
Our data did not show statistically significant differences in $\mathrm{F}_{\mathrm{T}}, \mathrm{F}_{\mathrm{S}}$ or $\mathrm{M}$ components of refraction between the nasal and temporal retina $(p>0.05)$.

\section{DISCUSSION}

With the present study we have shown that, with orthokeratology or corneal refractive therapy (CRT), peripheral refraction including $\mathrm{F}_{\mathrm{S}}$ and $\mathrm{F}_{\mathrm{T}}$ components change differently beyond the central $30^{\circ}$ of the visual field (the eye becomes more astigmatic). This is clear from the separation between the black lines (before treatment) and after treatment (grey lines) in Figure 2. The cause of this change is essentially due to the 
TABLE 2 Changes in RPRE $( \pm \mathrm{SD})$ after treatment for each eccentric nasal $(\mathrm{N})$ and temporal $(\mathrm{T})$ eye rotation, statistical significance for comparison between pre- and post-treatment $\left(p^{\mathrm{a}}\right)$ and significance for the comparison of post-treatment RPRE among groups $\left[p^{b}\right]$.

\begin{tabular}{|c|c|c|c|}
\hline Retinal location $\left(^{\circ}\right)$ & $\mathrm{M} \pm \mathrm{SD}\left(p^{\mathrm{a}}\right)$ & $\mathrm{F}_{\mathrm{T}} \pm \mathrm{SD}\left(p^{\mathrm{a}}\right)$ & $\mathrm{F}_{\mathrm{S}} \pm \mathrm{SD}\left(p^{\mathrm{a}}\right)$ \\
\hline \multicolumn{4}{|l|}{ N35 } \\
\hline 1 & $-1.03 \pm 0.33\left(<0.001^{*}\right)$ & $-1.57 \pm 0.41\left(<0.001^{*}\right)$ & $-0.48 \pm 0.42(0.016+)$ \\
\hline 2 & $-2.38 \pm 2.38(0.006+)$ & $-3.51 \pm 3.25(0.004+)$ & $-1.26 \pm 1.59(0.026+)$ \\
\hline 3 & $-3.40 \pm 1.20\left(<0.001^{*}\right)$ & $-4.68 \pm 1.30\left(<0.001^{*}\right)$ & $-2.10 \pm 1.42\left(<0.001^{*}\right)$ \\
\hline$\left[p^{\mathrm{b}}\right]$ & {$[0.010+]$} & {$[0.004+]$} & {$[0.109 *]$} \\
\hline \multicolumn{4}{|l|}{$\mathrm{N} 30$} \\
\hline 1 & $-0.77 \pm 0.45\left(<0.001^{*}\right)$ & $-1.30 \pm 0.56\left(<0.001^{*}\right)$ & $-0.24 \pm 0.52\left(0.165^{*}\right)$ \\
\hline 2 & $-1.85 \pm 2.29(0.013+)$ & $-2.77 \pm 3.19(0.007+)$ & $-0.92 \pm 1.47(0.037+)$ \\
\hline 3 & $-3.16 \pm 1.54\left(<0.001^{*}\right)$ & $-4.71 \pm 2.25\left(<0.001^{*}\right)$ & $-1.61 \pm 1.03\left(<0.001^{*}\right)$ \\
\hline$\left[p^{\mathrm{b}}\right]$ & {$[0.006+]$} & {$[0.001+]$} & {$[0.102+]$} \\
\hline \multicolumn{4}{|l|}{ N25 } \\
\hline 1 & $-0.58 \pm 0.57\left(0.008^{*}\right)$ & $-1.00 \pm 0.71\left(0.001^{*}\right)$ & $-0.14 \pm 0.52(0.286+)$ \\
\hline 2 & $-1.04 \pm 1.71(0.041+)$ & $-1.67 \pm 2.40(0.017+)$ & $-0.42 \pm 1.05(0.266+)$ \\
\hline 3 & $-2.27 \pm 0.98\left(<0.001^{*}\right)$ & $-3.42 \pm 1.47(0.002+)$ & $-1.11 \pm 0.77\left(<0.001^{*}\right)$ \\
\hline$\left[p^{\mathrm{b}}\right]$ & {$[0.009+]$} & {$[0.008+]$} & {$\left[0.206^{*}\right]$} \\
\hline \multicolumn{4}{|l|}{$\mathrm{N} 20$} \\
\hline 1 & $-0.29 \pm 0.65\left(0.175^{*}\right)$ & $-0.57 \pm 0.98\left(0.085^{*}\right)$ & $0.00 \pm 0.42(0.929+)$ \\
\hline 2 & $-0.82 \pm 1.04(0.004+)$ & $-1.30 \pm 1.57(0.008+)$ & $-0.34 \pm 0.65(0.100+)$ \\
\hline 3 & $-1.28 \pm 0.97(0.005+)$ & $-1.90 \pm 1.70\left(0.003^{*}\right)$ & $-0.65 \pm 0.48\left(0.001^{*}\right)$ \\
\hline$\left[p^{\mathrm{b}}\right]$ & {$[0.039+]$} & {$[0.031+]$} & {$\left[0.235^{*}\right]$} \\
\hline \multicolumn{4}{|l|}{ N15 } \\
\hline 1 & $-0.02 \pm 0.55\left(0.886^{*}\right)$ & $-0.12 \pm 0.78\left(0.620^{*}\right)$ & $0.07 \pm 0.49(0.625+)$ \\
\hline 2 & $-0.30 \pm 1.06(0.722+)$ & $-0.46 \pm 1.58(0.657+)$ & $-0.14 \pm 0.76(0.656+)$ \\
\hline 3 & $-0.16 \pm 0.55\left(0.340^{*}\right)$ & $-0.43 \pm 1.00(0.272+)$ & $0.12 \pm 0.54\left(0.454^{*}\right)$ \\
\hline$\left[p^{\mathrm{b}}\right]$ & {$[0.461+]$} & {$[0.758+]$} & {$[0.094+]$} \\
\hline \multicolumn{4}{|l|}{ N10 } \\
\hline 1 & $0.07 \pm 0.54\left(0.683^{*}\right)$ & $0.02 \pm 0.64\left(0.934^{*}\right)$ & $0.12 \pm 0.54(0.386+)$ \\
\hline 2 & $-0.15 \pm 0.87(0.859+)$ & $-0.06 \pm 1.16(0.756+)$ & $-0.23 \pm 0.66(0.266+)$ \\
\hline 3 & $0.05 \pm 0.60(0.556+)$ & $-0.02 \pm 1.03(0.530+)$ & $0.11 \pm 0.25\left(0.161^{*}\right)$ \\
\hline$\left[p^{\mathrm{b}}\right]$ & {$[0.448+]$} & {$[0.698+]$} & {$[0.164+]$} \\
\hline \multicolumn{4}{|l|}{ N5 } \\
\hline 1 & $0.09 \pm 0.28\left(0.328^{*}\right)$ & $0.04 \pm 0.43\left(0.791^{*}\right)$ & $0.13 \pm 0.18(0.033+)$ \\
\hline 2 & $-0.03 \pm 0.24\left(0.710^{*}\right)$ & $0.04 \pm 0.34\left(0.711^{*}\right)$ & $-0.10 \pm 0.34\left(0.372^{*}\right)$ \\
\hline 3 & $0.16 \pm 0.36(0.126+)$ & $0.06 \pm 0.59(0.814+)$ & $0.27 \pm 0.33(0.013+)$ \\
\hline$\left[p^{\mathrm{b}}\right]$ & {$\left[0.573^{*}\right]$} & {$\left[0.912^{*}\right]$} & {$\left[0.225^{*}\right]$} \\
\hline \multicolumn{4}{|l|}{ T5 } \\
\hline 1 & $0.06 \pm 0.25\left(0.456^{*}\right)$ & $0.10 \pm 0.26(0.444+)$ & $0.02 \pm 0.35\left(0.867^{*}\right)$ \\
\hline 2 & $0.03 \pm 0.16(0.838+)$ & $-0.04 \pm 0.22\left(0.538^{*}\right)$ & $0.10 \pm 0.26\left(0.219^{*}\right)$ \\
\hline 3 & $-0.07 \pm 0.46\left(0.624^{*}\right)$ & $-0.15 \pm 0.57\left(0.382^{*}\right)$ & $0.02 \pm 0.41(0.906+)$ \\
\hline$\left[p^{\mathrm{b}}\right]$ & {$\left[0.262^{*}\right]$} & {$\left[0.406^{*}\right]$} & {$\left[0.172^{*}\right]$} \\
\hline \multicolumn{4}{|l|}{$\mathrm{T} 10$} \\
\hline 1 & $0.09 \pm 0.32\left(0.363^{*}\right)$ & $0.05 \pm 0.42\left(0.679^{*}\right)$ & $0.13 \pm 0.30\left(0.180^{*}\right)$ \\
\hline 2 & $-0.09 \pm 0.19\left(0.175^{*}\right)$ & $-0.21 \pm 0.24\left(0.015^{\star}\right)$ & $0.04 \pm 0.33\left(0.668^{*}\right)$ \\
\hline 3 & $-0.34 \pm 0.61\left(0.078^{*}\right)$ & $-0.52 \pm 0.77(0.034+)$ & $-0.17 \pm 0.56\left(0.315^{*}\right)$ \\
\hline$\left[p^{\mathrm{b}}\right]$ & {$[0.039+]$} & {$[0.085+]$} & {$\left[0.013^{*}\right]$} \\
\hline \multicolumn{4}{|l|}{$\mathrm{T} 15$} \\
\hline 1 & $-0.13 \pm 0.39\left(0.302^{*}\right)$ & $-0.26 \pm 0.50\left(0.111^{*}\right)$ & $0.01 \pm 0.38\left(0.932^{*}\right)$ \\
\hline 2 & $-0.34 \pm 0.29\left(0.003^{*}\right)$ & $-0.72 \pm 0.40\left(<0.001^{*}\right)$ & $0.04 \pm 0.46\left(0.753^{*}\right)$ \\
\hline 3 & $-0.87 \pm 0.95\left(0.009^{*}\right)$ & $-1.37 \pm 1.45\left(0.007^{*}\right)$ & $-0.37 \pm 0.54\left(0.036^{*}\right)$ \\
\hline$\left[p^{\mathrm{b}}\right]$ & {$[0.076+]$} & {$[0.099+]$} & {$\left[0.008^{*}\right]$} \\
\hline \multicolumn{4}{|l|}{$\mathrm{T} 20$} \\
\hline 1 & $-0.47 \pm 0.33(0.003+)$ & $-0.78 \pm 0.58\left(0.001^{*}\right)$ & $-0.16 \pm 0.26\left(0.067^{*}\right)$ \\
\hline 2 & $-0.74 \pm 0.54\left(0.001^{*}\right)$ & $-1.29 \pm 0.78\left(<0.001^{*}\right)$ & $-0.18 \pm 0.47\left(0.219^{*}\right)$ \\
\hline 3 & $-1.70 \pm 1.66\left(0.005^{*}\right)$ & $-2.56 \pm 2.40\left(0.003^{*}\right)$ & $-0.83 \pm 1.02\left(0.017^{*}\right)$ \\
\hline$\left[p^{\mathrm{b}}\right]$ & {$[0.079+]$} & {$[0.064+]$} & {$[0.034+]$} \\
\hline \multicolumn{4}{|l|}{$\mathrm{T} 25$} \\
\hline 1 & $-0.72 \pm 0.19\left(<0.001^{*}\right)$ & $-1.17 \pm 0.43\left(<0.001^{*}\right)$ & $-0.28 \pm 0.21\left(0.002^{*}\right)$ \\
\hline 2 & $-1.21 \pm 0.94\left(0.002^{*}\right)$ & $-1.99 \pm 1.25\left(<0.001^{*}\right)$ & $-0.44 \pm 0.68\left(0.061^{*}\right)$ \\
\hline 3 & $-2.51 \pm 1.32\left(<0.001^{*}\right)$ & $-3.67 \pm 1.98\left(<0.001^{*}\right)$ & $-1.35 \pm 0.82\left(<0.001^{*}\right)$ \\
\hline$\left[p^{\mathrm{b}}\right]$ & {$[0.008+]$} & {$[0.004+]$} & {$\left[0.006^{*}\right]$} \\
\hline T30 & & & \\
\hline
\end{tabular}


TABLE 2 Continued

\begin{tabular}{|c|c|c|c|}
\hline Retinal location $\left(^{\circ}\right)$ & $\mathrm{M} \pm \mathrm{SD}\left(p^{\mathrm{a}}\right)$ & $\mathrm{F}_{\mathrm{T}} \pm \mathrm{SD}\left(p^{\mathrm{a}}\right)$ & $\mathrm{F}_{\mathrm{S}} \pm \mathrm{SD}\left(p^{\mathrm{a}}\right)$ \\
\hline 1 & $-1.20 \pm 0.50(0.003+)$ & $-1.75 \pm 0.60\left(<0.001^{*}\right)$ & $-0.65 \pm 0.45\left(0.001^{*}\right)$ \\
\hline 2 & $-1.60 \pm 1.11\left(0.001^{*}\right)$ & $-2.52 \pm 1.28\left(<0.001^{*}\right)$ & $-0.68 \pm 1.06\left(0.061^{*}\right)$ \\
\hline 3 & $-3.08 \pm 1.39\left(<0.001^{*}\right)$ & $-4.67 \pm 2.01\left(<0.001^{*}\right)$ & $-1.48 \pm 1.03\left(<0.001^{*}\right)$ \\
\hline$\left[p^{\mathrm{b}}\right]$ & {$[0.005+]$} & {$[0.001+]$} & {$[0.122+]$} \\
\hline \multicolumn{4}{|l|}{ T35 } \\
\hline 1 & $-1.72 \pm 0.47\left(<0.001^{*}\right)$ & $-2.58 \pm 0.61\left(<0.001^{*}\right)$ & $-0.84 \pm 0.48\left(<0.001^{*}\right)$ \\
\hline 2 & $-2.01 \pm 1.16\left(<0.001^{*}\right)$ & $-3.21 \pm 1.31\left(<0.001^{*}\right)$ & $-0.80 \pm 1.16\left(0.045^{*}\right)$ \\
\hline 3 & $-3.78 \pm 1.07\left(<0.001^{*}\right)$ & $-5.57 \pm 1.45\left(<0.001^{*}\right)$ & $-1.98 \pm 0.98\left(<0.001^{*}\right)$ \\
\hline$\left[p^{\mathrm{b}}\right]$ & {$[0.001+]$} & {$[0.001+]$} & {$[0.029+]$} \\
\hline
\end{tabular}

$\left.{ }^{*}\right)$ parametric tests; $(+)$ Non-parametric tests; boldface: $p<0.05$.

myopic trend of the tangential focal length, while the sagittal focal length changes minimally for low and mild myopes, and to a greater extent in the higher myopes. However, the changes in the sagittal focal length are much lower compared to the changes observed in the tangential focal length. Moreover, the results show that the change in the position of the focal lengths in the periphery of the visual field is related with the baseline refractive error, particularly in the temporal side of the retina. We hypothesize that the relationship between the change in RPRE and baseline axial myopia is related with the changes operated in the anterior corneal surface for different degrees of myopia during orthokeratology treatment for myopia; similar behavior has been also described for corneal refractive surgery. ${ }^{11,26,27}$ The amount of curvature change in the anterior corneal surface is intrinsically related with the amount of myopia to be corrected. Lower myopia requires a lower degree of corneal reshaping than higher myopia. It has been previously shown that changes in RPRE after orthokeratology involve large amounts of induced astigmatism. When the spherical equivalent is considered, the peripheral refraction becomes myopic. However, when the two focal distances are considered, we observe that the curvature changes in the anterior corneal surface at the edge of the treatment zone create a greater myopic effect on the tangential image shell, leaving the sagittal image shell relatively unchanged for lower degrees of corneal reshaping.

Orthokeratology has experienced a rebirth in recent years becoming one of the most promising techniques to reduce the progression of myopia.,28 Indeed, currently, up to four different studies have demonstrated similar degrees of effectiveness of orthokeratology in Hong-Kong, ${ }^{7}$ Spain ${ }^{8}$ USA $^{9}$ and Japan, ${ }^{6}$ with retention rates going up to 56 and 36\%, when compared with the respective control groups. Furthermore, in the Japanese study, Hiraoka et al. demonstrated a consistent effect of retention of $30 \%$ over a period of 5 years. ${ }^{29}$ It has been suggested that the mechanism behind myopia retention in orthokeratology is linked with the changes in corneal shape, that seem to be responsible for inducing peripheral myopization, ${ }^{11,30}$ while the central visual field remains well corrected for a sharp visual acuity. Despite this, the role of peripheral refraction in myopia progression is still unknown and controversial. While animal studies support the effectiveness in myopia control achieved with peripheral myopization combined with a sharp central vision, human studies have failed to demonstrate such a dose-effect relationship. Peripheral myopization expressed as $\mathrm{M}$ component shows a relationship between baseline refractive error and degree of peripheral myopia induced in the paracentral cornea. ${ }^{11}$ On light of this information, it would be expected that the higher the degree of peripheral myopia, the higher the retention effect. However, several clinical trials have failed to find a correlation between biometric or refractive baseline data and myopia correction. Hiraoka et al. showed a poor correlation between the baseline refractive error and axial elongation over a period of 2 years. $^{6}$

Much work has been conducted showing the changes in peripheral refraction after orthokeratology, but none has addressed the changes in sagittal and tangential components of the astigmatic refraction that is, the post-treatment field curvatures in both principal planes of refraction. The present study allowed us to evaluate the changes in different components of refraction for subjects with different degrees of myopia. While spherical equivalent refraction as well as $\mathrm{F}_{\mathrm{T}}$ shows a consistent post-treatment change in the myopic direction, sagittal power error $\left(F_{S}\right)$ remains hyperopic for a significant number of subjects. If relative peripheral hyperopia drives myopic increase, our results show that $F_{S}$ could be more relevant in myopia progression has previously demonstrated in monkeys, where in the presence of mixed astigmatism the animal's eyes grew towards the most posterior astigmatic focal plane $\left(\mathrm{F}_{\mathrm{S}}\right)^{2,25}$ Indeed, at baseline RPRE in the sagittal plane was 
hyperopic for almost all of our subjects in the nasal and temporal peripheral visual field. After treatment, a significant part of our subjects showed a change towards myopia while some of them still remained hyperopic. By analyzing the data by different degrees of baseline myopia (Figure 2), we observe that for low myopes $F_{S}$ remains hyperopic, for mild myopes the nasal retina becomes myopic while the temporal retina remains hyperopic and for moderate-to-high myopes RPRE becomes myopic in both sides of the visual field. Furthermore, it is clear that as the degree of baseline myopia increases so does the gap between $\mathrm{F}_{\mathrm{S}}$ and $\mathrm{F}_{\mathrm{T}}$. In the future, optical devices might allow to control the overall amount of peripheral astigmatism in such a way that $F_{S}$ might becomes increasingly myopic. Additionally, methods of correction might deal also with the degree of asymmetry between both hemifields of the retina that might be related with the natural anatomy of the myopic eye, that shows a shorter eye length in the temporal retina, making it more difficult to achieve a myopization effect. ${ }^{18}$ Orthokeratology is usually associated with a symmetric change in the RPRE between nasal and temporal retina, ${ }^{10,11}$ and this study agrees with this view. However, other treatments have shown an asymmetric ability to change the RPRE in myopic eyes. ${ }^{31-34}$ Whether a consistent myopization effect is to be achieved in both sagittal and tangential focal planes across the entire peripheral retina, or if some retinal area should be specifically treated, this raises the question of regional control of the refractive effect to improve treatment's efficacy. In this domain, the inherent anatomical specificities of the myopic eyes with different degrees of axial elongation should be considered. ${ }^{18,35,36}$

In summary, orthokeratology treatment does not guarantee peripheral myopization in all degrees of myopia being treated. While the treatment achieves an increase in myopic relative peripheral refractive error for both $\mathrm{F}_{\mathrm{S}}$ and $\mathrm{F}_{\mathrm{T}}$ components, this effect seems to be insufficient for the lower myopes due to the lower corneal changes induced by orthokeratology in lower treatments.

\section{ACKNOWLEDGMENTS}

The authors want to thank Paragon Vision Science (Mesa. AZ) for donating the lenses.

\section{DECLARATION OF INTEREST}

This work was partially funded by Fundação para Ciência e Tecnologia, Portugal, Projects: PTDC/SAUBEB/098392/2008 and PTDC/SAU-BEB/098391/ 2008 and the Strategic Project PEST-C/FIS/UI607/ 2011.

\section{REFERENCES}

1. Kempen JH, Mitchell P, Lee KE, Tielsch JM, Broman AT, Taylor HR, et al. The prevalence of refractive errors among adults in the United States, Western Europe, and Australia. Arch Ophthalmol 2004;122:495-505.

2. Gonzalez-Meijome JM, Villa-Collar C. Nomogram, corneal topography, and final prescription relations for corneal refractive therapy. Optom Vis Sci 2007;84:59-64.

3. Cho P, Cheung SW. Retardation of myopia in Orthokeratology (ROMIO) study: a 2-year randomized clinical trial. Invest Ophthalmol Vis Sci 2012;53:7077-7085.

4. Santodomingo-Rubido J, Villa-Collar C, Gilmartin B, Gutierrez-Ortega R. Orthokeratology vs. spectacles: adverse events and discontinuations. Optom Vis Sci 2012; 89:1133-1139.

5. Santodomingo-Rubido J, Villa-Collar C, Gilmartin B, Gutierrez-Ortega R. Myopia control with orthokeratology contact lenses in Spain: a comparison of vision-related quality-of-life measures between orthokeratology contact lenses and single-vision spectacles. Eye Contact Lens 2013; 39:153-157.

6. Kakita T, Hiraoka T, Oshika T. Influence of overnight orthokeratology on axial elongation in childhood myopia. Invest Ophthalmol Vis Sci 2011;52:2170-2174.

7. Cho $\mathrm{P}$, Cheung SW, Edwards $\mathrm{M}$. The longitudinal orthokeratology research in children (LORIC) in Hong Kong: a pilot study on refractive changes and myopic control. Curr Eye Res 2005;30:71-80.

8. Santodomingo-Rubido J, Villa-Collar C, Gilmartin B, Gutierrez-Ortega R. Myopia control with orthokeratology contact lenses in Spain: refractive and biometric changes. Invest Ophthalmol Vis Sci 2012;53:5060-5065.

9. Walline JJ, Jones LA, Sinnott LT. Corneal reshaping and myopia progression. Br J Ophthalmol 2009;93:1181-1185.

10. Charman WN, Mountford J, Atchison DA, Markwell EL. Peripheral refraction in orthokeratology patients. Optom Vis Sci 2006;83:641-648.

11. Queiros A, Gonzalez-Meijome JM, Jorge J, Villa-Collar C, Gutierrez AR. Peripheral refraction in myopic patients after orthokeratology. Optom Vis Sci 2010;87:323-329.

12. Smith EL III, Kee CS, Ramamirtham R, Qiao-Grider $Y$, Hung LF. Peripheral vision can influence eye growth and refractive development in infant monkeys. Invest Ophthalmol Vis Sci 2005;46:3965-3972.

13. Smith EL III, Ramamirtham R, Qiao-Grider Y, Hung LF, Huang J, Kee CS, et al. Effects of foveal ablation on emmetropization and form-deprivation myopia. Invest Ophthalmol Vis Sci 2007;48:3914-3922.

14. Diether S, Schaeffel F. Local changes in eye growth induced by imposed local refractive error despite active accommodation. Vision Res 1997;37:659-668.

15. Bakaraju RC, Ehrmann K, Papas E, Ho A. Do peripheral refraction and aberrations profiles vary with the type of myopia? - an illustration using a ray-tracing approach. J Optom 2009;2:29-38.

16. Chen Z, Niu L, Xue F, Qu X, Zhou Z, Zhou X, Chu R. Impact of pupil diameter on axial growth in orthokeratology. Optom Vis Sci 2012;89:1636-1640.

17. Flitcroft DI. The complex interactions of retinal, optical and environmental factors in myopia aetiology. Prog Retin Eye Res 2012;31:622-660.

18. Faria-Ribeiro M, Queiros A, Lopes-Ferreira D, Jorge J, Gonzalez-Meijome JM. Peripheral refraction and retinal contour in stable and progressive myopia. Optom Vis Sci 2013;90:9-15.

19. Charman WN. Myopia, posture and the visual environment. Ophthalmic Physiol Opt 2011;31:494-501. 
20. Kee CS, Hung LF, Qiao-Grider Y, Roorda A, Smith III EL. Effects of optically imposed astigmatism on emmetropization in infant monkeys. Invest Ophthalmol Vis Sci 2004;45: 1647-1659.

21. Thibos LN, Wheeler W, Horner D. Power vectors: an application of Fourier analysis to the description and statistical analysis of refractive error. Optom Vis Sci 1997; 74:367-375.

22. Queiros A, Gonzalez-Meijome J, Jorge J. Influence of fogging lenses and cycloplegia on open-field automatic refraction. Ophthalmic Physiol Opt 2008;28:387-392.

23. Davies LN, Mallen EA, Wolffsohn JS, Gilmartin B. Clinical evaluation of the Shin-Nippon NVision-K 5001/Grand Seiko WR-5100K autorefractor. Optom Vis Sci 2003;80: 320-324.

24. Queiros A, Jorge J, Gonzalez-Meijome JM. Influence of fogging lenses and cycloplegia on peripheral refraction. J Optom 2009;2:83-89.

25. Lu F, Simpson T, Sorbara L, Fonn D. The relationship between the treatment zone diameter and visual, optical and subjective performance in corneal refractive therapy lens wearers. Ophthalmic Physiol Opt 2007;27:568-578.

26. Queiros A, Villa-Collar C, Jorge J, Gutierrez AR, GonzalezMeijome JM. Peripheral refraction in myopic eyes after LASIK surgery. Optom Vis Sci 2012;89:977-983.

27. Gonzalez-Meijome JM, Sanudo-Buitrago F, LopezAlemany A, Almeida JB, Parafita MA. Correlations between central and peripheral changes in anterior corneal topography after myopic LASIK and their implications in postsurgical contact lens fitting. Eye Contact Lens 2006;32: 197-202.

28. Cheung SW, Cho P, Fan D. Asymmetrical increase in axial length in the two eyes of a monocular orthokeratology patient. Optom Vis Sci 2004;81:653-656.
29. Hiraoka T, Kakita T, Okamoto F, Takahashi H, Oshika $\mathrm{T}$. Long-term effect of overnight orthokeratology on axial length elongation in childhood myopia: a 5-year follow-up study. Invest Ophthalmol Vis Sci 2012;53: 3913-3919.

30. Queiros A, Villa-Collar C, Gonzalez-Meijome JM, Jorge J, Gutierrez AR. Effect of pupil size on corneal aberrations before and after standard laser in situ keratomileusis, custom laser in situ keratomileusis, and corneal refractive therapy. Am J Ophthalmol 2010;150:97-109.

31. Sankaridurg P, Donovan L, Varnas S, Ho A, Chen X, Martinez A, et al. Spectacle lenses designed to reduce progression of myopia: 12-month results. Optom Vis Sci 2010;87:631-641.

32. Sankaridurg P, Holden B, Smith E III, Naduvilath T, Chen $X$, de la Jara PL, et al. Decrease in rate of myopia progression with a contact lens designed to reduce relative peripheral hyperopia: one-year results. Invest Ophthalmol Vis Sci 2011;52:9362-9367.

33. Lopes-Ferreira D, Ribeiro C, Maia R, García-Porta N, Queirós A, Villa-Collar C, González-Méijome JM. Peripheral myopization using a dominant design multifocal contact lens. J Optom 2011;4:14-21.

34. Lopes-Ferreira D, Ribeiro C, Neves H, Faria-Ribeiro M, Queirós A, Villa-Collar C, et al. Peripheral refraction with dominant design multifocal contact lenses in young myopes. J Optom 2013;6:85-94.

35. Singh KD, Logan NS, Gilmartin B. Three-dimensional modeling of the human eye based on magnetic resonance imaging. Invest Ophthalmol Vis Sci 2006;47: 2272-2279.

36. Logan NS, Gilmartin B, Dunne MC. Computation of retinal contour in anisomyopia. Ophthalmic Physiol Opt 1995;15: 363-366. 